\title{
Article \\ Effects of Storage Conditions on the Flavor Stability of Fried Pepper (Zanthoxylum bungeanum) Oil
}

\author{
Jie Sun ${ }^{1,2}$, Baoguo Sun ${ }^{1}$, Fazheng Ren ${ }^{2}$, Haitao Chen ${ }^{1, *}$, Ning Zhang ${ }^{1}$, Yuyu Zhang ${ }^{1}$ and Huiying Zhang $^{1}$ \\ 1 Beijing Key Laboratory of Flavor Chemistry, Beijing Technology and Business University, \\ Beijing 100048, China; sunjeel@163.com (J.S.); sunbg@btbu.edu.cn (B.S.); zh_ningts@btbu.edu.cn (N.Z.); \\ zhangyuyu@btbu.edu.cn (Y.Z.); zhanghuiying@btbu.edu.cn (H.Z.) \\ 2 Beijing Advanced Innovation Center for Food Nutrition and Human Health, College of Food Science \& \\ Nutritional Engineering, China Agricultural University, Beijing 100083, China; renfazheng@cau.edu.cn \\ * Correspondence: chenht@th.btbu.edu.cn; Tel.: +86-10-68985219
}

check for updates

Citation: Sun, J.; Sun, B.; Ren, F.; Chen, H.; Zhang, N.; Zhang, Y.; Zhang, H. Effects of Storage Conditions on the Flavor Stability of Fried Pepper (Zanthoxylum bungeanum) Oil. Foods 2021, 10, 1292. https://doi.org/10.3390/foods10061292

Academic Editor: Maria D. Guillen

Received: 28 April 2021

Accepted: 28 May 2021

Published: 4 June 2021

Publisher's Note: MDPI stays neutral with regard to jurisdictional claims in published maps and institutional affiliations.

Copyright: (C) 2021 by the authors. Licensee MDPI, Basel, Switzerland. This article is an open access article distributed under the terms and conditions of the Creative Commons Attribution (CC BY) license (https:// creativecommons.org/licenses/by/ $4.0 /)$.

\begin{abstract}
Flavor stability of fried pepper oil was investigated during 30 days of storage. Variation trends of key volatile flavor compounds in fried pepper oil induced by ultraviolet (UV) irradiation and oxygen $\left(\mathrm{O}_{2}\right)$ exposure were compared using GC-MS and chiral GC-MS analysis. Chirality analysis showed that conversion of (S)-(-)-limonene to (R)-(+)-limonene form was observed during storage. The storage conditions did not change the configuration of linalool, linalool oxide, or carvone. Quantitative analysis showed that the concentrations of linalool, limonene, 1,8-cineole, $\beta$-myrcene, and $\beta$-ocimene decreased dramatically during storage, whereas carvone, (E)-2-heptenal, and linalool oxide showed an increasing trend during storage. The loss rate of limonene and linalool exhibited the highest under combined UV and $\mathrm{O}_{2}$ condition, which played an important role for the aroma attenuation of pepper oil. This result will benefit the storage of pepper oil and based on pepper oil aromatic products.
\end{abstract}

Keywords: fried pepper oil; ultraviolet (UV) irradiation; oxygen exposure; storage; aroma attenuation

\section{Introduction}

Zanthoxylum bungeanum Maxim. belongs to the Zanthoxylum genus in Ruratceae and is estimated to have 250 species throughout the world [1]. In China, it is also known as Chinese pepper or huajiao. With the deepening of targeted poverty alleviation efforts, Chinese pepper, as an efficient agricultural product for farming, has been widely planted across the country. In recent years, the total production of Chinese pepper has shown a fluctuating growth trend. According to statistics from the China Forestry Yearbook, the output of dried Chinese pepper has remained above 300,000 tons since 2012. Production increased to 438,400 tons in 2017 and to approximately 458,500 tons in 2018. Because of its dual medicinal and edible purposes, it has become one of the hotspots of research by scientific researchers and manufacturing companies.

Zanthoxylum bungeanum Maxim. is popular among consumers because of its unique and mouth-watering aroma and taste. The composition of Zanthoxylum bungeanum Maxim. volatiles has been studied in depth and found to be mainly composed of monoterpenes [2-4]. Jiang et al. [5] reported that geraniol, citronellal, linalool, and methyl cinnamate were perceived to be important to the basic flavor of green and ripe fruits and dried pericarp of Japanese pepper. Yang et al. [6] compared the volatile flavor compounds of Sichuan red pepper and green pepper, and found that linalool, $\alpha$-terpineol, myrcene, and 1,8-cineole were the main aroma compounds of the two types of pepper. As the main deep-processed product of Chinese pepper, fried pepper oil is widely used in various foods. Our previous research on the flavor compounds of fried pepper oil showed that 1,8-cineole, (E)-2-heptenal, $\beta$-myrcene, $\beta$-ocimene, limonene, and linalool were the major aroma active compounds in pepper oil from two regions (Hancheng and Hanyuan) through solvent-assisted flavor 
evaporation combined with gas chromatography-mass spectrometry and aroma extract dilution analysis [7].

However, the flavor intensity of fried pepper oil could decay after a period of storage when it was kept under sunlight at room temperature. Fried pepper oil contained a large number of terpenoids, and studies have shown that terpenoids were very susceptible to oxygen and ultraviolet radiation [8]. As long as there was oxygen, even at a low concentration, terpenoids could undergo oxidation reactions. The resulting oxidation products would be further degraded due to unstable structure and produce volatile components such as alcohols, aldehydes, and ketones [8]. In addition, previous studies have shown that storage conditions (such as storage time, temperature, light, and oxygen) may have a significant impact on the aroma of essential oils. Sun et al. found the pummelo essential oil could deteriorate very quickly with a strong oily off-flavor, for which UV sunlight was revealed to be the critical contributor causing the chemical reactions for the aroma changes [9]. Cheng et al. [10] investigated the changes of limonene and linalool in pepper flavoring oil under different storage conditions and found the contents of limonene and linalool were significantly reduced under sunlight irradiation. Moreover, due to the influence of factors such as $\mathrm{pH}$ and temperature, many chiral molecules in terpenoids can be transformed from one form to another, thereby changing the aroma quality of the products [11]. It has been reported that both (S)-a-terpineol and (S)-4-terpineol in the hard tea beverage dominated at beginning of the storage, but (R)-(+)-a-terpineol became dominated after storage; thus, racemization affected the flavor stability of the hard tea beverage [12]. Therefore, the changes of terpenoids under different storage conditions were crucial to the aromatic profiles of fried pepper oil.

Despite all this, studies on the effects of UV irradiation and oxygen exposure on the aromatic changes of fried pepper oil are still limited. In the previous study, our research team reported that 1,8-cineole, (E)-2-heptenal, $\beta$-myrcene, $\beta$-ocimene, limonene, linalool, linalool oxide, and carvone were the key volatile flavor compounds in fried pepper oil [7]. Therefore, the objective of the study was to analyze the effect of UV irradiation and oxygen exposure on above-mentioned volatile flavor compounds and elucidate the key volatiles responsible for the aroma changes after UV irradiation and oxygen exposure.

\section{Materials and Methods}

\subsection{Materials}

Dried Hanyuan (HY) pepper samples were purchased from You Jia Co., Ltd. (Yaan City, Sichuan Province, China). Fresh peppers were harvested in September 2020 and dried by hot air. Corn germ oil was purchased from Jin Long Yu Co., Ltd. (Qinhuangdao City, Hebei Province, China).

\subsection{Chemicals}

Limonene ( $\geq 95 \%), \beta$-ocimene (95\%), (E)-2-heptenal (95\%), 1,8-cineole (99\%), carvone ( $\geq 95 \%), \beta$-myrcene (95\%), linalool (98\%), linalool oxide (97\%), and n-alkane (C6-C30, $\geq 99 \%)$ standards and the internal standard 4-octanol ( $\geq 99 \%)$ were purchased from SigmaAldrich (Shanghai, China). Dichloromethane and sodium sulfate were purchased from Thermo Fisher (Beijing, China). Enantiomer standards including S-(-)-limonene (96\%), R-(+)-limonene (97\%), R-(-)-linalool (97\%), R-(-)-carvone (97\%), and S-(+)-carvone (97\%) were purchased from Sigma Aldrich (Shanghai, China).

\subsection{Fried Pepper Oil Sample Preparation}

Corn germ oil $(150 \mathrm{~g})$ was heated to $130^{\circ} \mathrm{C}$ in an oil bath. Then, dry pepper granules $(25 \mathrm{~g})$ were added to the corn germ oil and fried at $130{ }^{\circ} \mathrm{C}$ continuously for $20 \mathrm{~min}$. During frying, the mixture was constantly stirred to prevent local overheating. The pepper oil was cooled to room temperature using an ice-water bath, and the pepper granules were removed. The prepared pepper oil was immediately subjected to a storage experiment. 


\subsection{Pepper Oil with Different Storage Conditions}

The effects of UV irradiation and oxygen exposure on the aroma quality of pepper oil were investigated at room temperature. The experimental samples were divided into four groups with label numbers $1-4$. The sample (with three replicates each) for each storage time (each two days) was measured for a total of 30 days. Detailed sample preparation was as follows:

(1) The No. 1 sample was only treated with UV irradiation. The pepper oil (100 g) sample was stored in a transparent and sealed glass bottle, and nitrogen $(99.9 \%)$ was filled into the bottle to discharge the air. Then, the glass bottles were placed in an incubator and exposed under four ultraviolet lights with peak emission at $254 \mathrm{~nm}$ at a distance of $10 \mathrm{~cm}$ for 30 days under a power of $10 \mathrm{~W}$. The temperature of the incubator was controlled at $25^{\circ} \mathrm{C}$.

(2) The No. 2 sample was only treated with oxygen exposure. The pepper oil (100 g) sample was stored in a transparent and sealed glass bottle with wrapped aluminum foil. Then, the glass bottles were placed in an incubator at $25^{\circ} \mathrm{C}$. Oxygen was injected into the glass bottles every 2 days.

(3) The No. 3 sample that was simultaneously treated with UV irradiation and oxygen exposure. The subsequent procedures followed those for sample 1. Oxygen was injected into the glass bottles every 2 days.

(4) The No. 4 sample (newly prepared pepper oil) was directly analyzed.

\subsection{Separation of Volatile Compounds}

Pepper oil (50 g) was dissolved in dichloromethane $(200 \mathrm{~mL})$ by shaking at $120 \mathrm{rpm}$ (grant OLS200, Cambridgeshire, UK) for $0.5 \mathrm{~h}$. Additionally, 4-octanol with a concentration of $8.2 \mathrm{mg} / \mathrm{L}$ was added as internal standard before the extraction procedure. The solutions were then subjected to high-vacuum distillation using SAFE. The resulting distillate was dried over anhydrous $\mathrm{Na}_{2} \mathrm{SO}_{4}$ and filtered. The final distillate was concentrated to 6-8 $\mathrm{mL}$ using a Vigreux column $(50 \times 1 \mathrm{~cm})$ (Beijing Jingxing Glassware Co., Ltd., Beijing, China) and then further concentrated to $1 \mathrm{~mL}$ with a nitrogen blower.

\subsection{GC-MS Analysis and Chiral GC-MS Analysis}

The analysis methods were performed according to Sun et al. [7]. GC-MS analysis was performed by a Thermo Fisher Trace 1310 gas chromatograph (Thermo Fisher Scientific, Waltham, MA, USA) coupled with a Thermo Fisher mass spectrometer (Thermo Fisher Scientific). Separation was performed with TG-Wax $(30 \mathrm{~m} \times 0.25 \mathrm{~mm}$ i.d., $0.25 \mu \mathrm{m}$, Thermo Fisher Scientific). The oven temperature was initially $40{ }^{\circ} \mathrm{C}$, followed by a $1 \mathrm{~min}$ hold; increased to $140{ }^{\circ} \mathrm{C}$ at a rate of $2{ }^{\circ} \mathrm{C} / \mathrm{min}$, followed by a $1 \mathrm{~min}$ hold; and finally increased to $220^{\circ} \mathrm{C}$ at a rate of $6{ }^{\circ} \mathrm{C} / \mathrm{min}$, followed by a $1 \mathrm{~min}$ hold. A Trace GC-MS system was used for chiral GC-MS analysis. The GC system was equipped with a 2,3-dimethyl-6-tertbutyldimethylchlorosilane- $\beta$-cyclodextrin capillary column $(30 \mathrm{~m} \times 0.25 \mathrm{~mm}$ i.d., $0.25 \mu \mathrm{m})$ from BGB (Switzerland). The mass detector conditions were as follows: ionization energy, $70 \mathrm{eV}$; ion source temperature, $250{ }^{\circ} \mathrm{C}$; mass range, $\mathrm{m} / \mathrm{z} 35-300$; and solvent delay, $5 \mathrm{~min}$.

\subsection{Identification and Quantitation}

Volatile flavor compounds were identified by comparing their retention indices (RIs), mass spectra, and standard reference compounds. The correction concentrations of each aroma compound were calculated according to the 4-octanol internal standard.

\subsection{Loss or Grow Rate of Key Volatile Compounds}

The loss rate or grow rate of key flavor compounds in fried pepper oil was calculated as follows:

$$
p=\frac{m_{1}-m_{2}}{m_{1}}
$$


where $p$ represents the loss rate or grow rate of key flavor compounds, $m_{1}$ is the concentration of key aroma compounds in the control pepper oil sample, and $m_{2}$ is the concentration of key aroma compounds in the pepper oil sample stored for 30 days.

\subsection{Statistical Analysis}

The experimental results were expressed as the mean \pm standard deviation (SD) and analyzed by one-way analysis of variance (ANOVA) using SPSS-IBM 19.0 software. Tukey's post hoc test $(p<0.05)$ was performed to compare significantly different means and samples. The figures were drawn using Origin 2018 software (OriginLab, Northampton, MA, USA).

\section{Results and Discussion}

\subsection{Effects of Different Storage Conditions on Enantiomer Ratios of Chiral Compounds}

It has been confirmed that the enantiomer of a chiral compound usually has different flavor characteristics and odor threshold [13]. Enantiomeric composition of limonene, linalool, linalool oxide, and carvone were investigated in this study by chiral GC-MS and by using the retention times of authentic reference standards as well as mass spectra (Table 1). The results showed that S-(-)-limonene, S-(+)-linalool, R-(-)-carvone, and 2R, $5 \mathrm{R}$-linalool oxide were the major isomers, respectively, in newly prepared fried pepper oil. Li et al. reported that a conversion of (R)-(-)-linalool to (S)-(+) form in the hard tea beverage was observed at a higher temperature during storage [12]. Therefore, changes in the enantiomeric ratio of key compounds in pepper oil under different storage conditions could affect the overall flavor of pepper oil.

Table 1. Odor description of enantiomers identified in newly prepared fried pepper oil.

\begin{tabular}{cc}
\hline Compound & Odor Description [7] \\
\hline S-(-)-limonene & lemon-like \\
R-(+)-limonene & orange-like \\
R-(-)-linalool & woody and lavender-like \\
S-(+)-linalool & sweet, floral, petitgrain-like \\
S-(+)-carvone & caraway-like \\
R-(-)-carvone & spearmint-like \\
2R, 5R-linalool oxide & floral \\
2S, 5S-linalool oxide & floral \\
\hline
\end{tabular}

The enantiomeric composition changes of limonene, linalool, linalool oxide, and carvone under different storage conditions were listed in Table 2. In 30 days of storage, (S)/(R) ratio of limonene decreased due to the conversion of S-limonene to R-limonene when treated solely with UV irradiation or oxygen exposure. Under UV irradiation and oxygen exposure conditions, an increase of R-limonene and decrease of S-limonene were observed. At 20 days of storage, S-limonene and R-limonene accounted for the same ratio, and Rlimonene began to dominate after 20 days of storage. Therefore, limonene was dominated by R-limonene when stored for 30 days. Under UV irradiation alone, the ratio of S-linalool decreased from 90 to 85 . The ratio of S-linalool decreased from 90 to 87 solely under oxygen exposure. Under UV irradiation-oxygen exposure $\left(\mathrm{UV}-\mathrm{O}_{2}\right)$, the ratio of S-linalool decreased from 90 to 86 . Although the enantiomer ratio of linalool changed under different storage conditions, S-linalool was still dominant after 30 days of storage. Only under UV irradiation, the ratio of $2 \mathrm{R}, 5 \mathrm{R}$-linalool oxide decreased from 53 to 49 . The ratio of $2 \mathrm{R}$, $5 \mathrm{R}$-linalool oxide decreased from 53 to 50 solely under oxygen exposure, and the ratio of 2R, 5R-linalool oxide decreased from 53 to 49 under $\mathrm{UV}-\mathrm{O}_{2}$. When stored for 30 days under different storage conditions, although the linalool oxide was dominated by $2 \mathrm{~S}$, 5S-linalool oxide, compared with the enantiomeric ratio of the linalool oxide in the original pepper oil, there was little change in the ratio. Under different storage conditions, the enantiomer ratio of carvone changed the same as that of linalol. Although the enantiomer ratio changed, R-carvone was still dominant after 30 days of storage. 
Table 2. Enantiomer ratio of chiral compounds in pepper oil under different storage conditions.

\begin{tabular}{|c|c|c|c|c|c|c|c|c|c|c|c|c|c|c|c|c|c|}
\hline \multirow[b]{2}{*}{ Storage Conditions ${ }^{\text {a }}$} & \multirow[b]{2}{*}{ Compound } & \multicolumn{16}{|c|}{ Enantiomeric Ratio } \\
\hline & & $\operatorname{con}^{b}$ & $2 \mathrm{~d}^{\mathrm{c}}$ & $4 \mathrm{~d}$ & $6 \mathrm{~d}$ & $8 \mathrm{~d}$ & $10 \mathrm{~d}$ & $12 \mathrm{~d}$ & $14 \mathrm{~d}$ & $16 \mathrm{~d}$ & $18 \mathrm{~d}$ & $20 \mathrm{~d}$ & $22 \mathrm{~d}$ & $24 \mathrm{~d}$ & $26 \mathrm{~d}$ & $28 \mathrm{~d}$ & $30 \mathrm{~d}$ \\
\hline \multirow{8}{*}{ UV } & S-(-)-limonene & 60 & 60 & 60 & 59 & 58 & 58 & 55 & 57 & 55 & 55 & 55 & 55 & 53 & 53 & 52 & 52 \\
\hline & $\mathrm{R}-(+)$-limonene & 40 & 40 & 40 & 41 & 42 & 42 & 45 & 43 & 45 & 45 & 45 & 45 & 47 & 47 & 48 & 48 \\
\hline & 2R, 5R-linalool oxide & 53 & 51 & 51 & 51 & 51 & 50 & 51 & 51 & 51 & 51 & 50 & 50 & 50 & 50 & 50 & 49 \\
\hline & 2S, 5S-linalool oxide & 47 & 49 & 49 & 49 & 49 & 50 & 49 & 49 & 49 & 49 & 50 & 50 & 50 & 50 & 50 & 51 \\
\hline & R-(-)-linalool & 10 & 10 & 11 & 11 & 11 & 11 & 11 & 11 & 11 & 12 & 12 & 12 & 12 & 13 & 14 & 15 \\
\hline & S-(+)-linalool & 90 & 90 & 89 & 89 & 89 & 89 & 89 & 89 & 89 & 88 & 88 & 88 & 88 & 87 & 86 & 85 \\
\hline & R-(-)-carvone & 55 & 56 & 56 & 56 & 56 & 56 & 56 & 55 & 55 & 54 & 54 & 54 & 54 & 52 & 52 & 52 \\
\hline & S-(+)-carvone & 45 & 44 & 44 & 44 & 44 & 44 & 44 & 45 & 45 & 46 & 46 & 46 & 46 & 48 & 48 & 48 \\
\hline \multirow{7}{*}{$\mathrm{O}_{2}$} & R-(+)-limonene & 40 & 41 & 43 & 43 & 43 & 45 & 45 & 45 & 46 & 47 & 47 & 48 & 48 & 48 & 49 & 49 \\
\hline & 2R, 5R-linalool oxide & 53 & 53 & 53 & 53 & 53 & 52 & 52 & 52 & 52 & 52 & 52 & 52 & 51 & 51 & 51 & 50 \\
\hline & 2S, 5S-linalool oxide & 47 & 47 & 47 & 47 & 47 & 48 & 48 & 48 & 48 & 48 & 48 & 48 & 49 & 49 & 49 & 50 \\
\hline & R-(-)-linalool & 10 & 10 & 11 & 11 & 11 & 11 & 11 & 11 & 11 & 11 & 12 & 12 & 12 & 13 & 13 & 13 \\
\hline & S-(+)-linalool & 90 & 90 & 89 & 89 & 89 & 89 & 89 & 89 & 89 & 89 & 88 & 88 & 88 & 87 & 87 & 87 \\
\hline & R-(-)-carvone & 55 & 54 & 53 & 53 & 53 & 53 & 53 & 52 & 52 & 52 & 52 & 52 & 52 & 52 & 52 & 51 \\
\hline & S-(+)-carvone & 45 & 46 & 47 & 47 & 47 & 47 & 47 & 48 & 48 & 48 & 48 & 48 & 48 & 48 & 48 & 49 \\
\hline \multirow{6}{*}{$\mathrm{UV}-\mathrm{O}_{2}$} & S-(-)-limonene & 60 & 58 & 58 & 57 & 55 & 56 & 57 & 55 & 55 & 55 & 54 & 53 & 50 & 50 & 50 & 48 \\
\hline & R-(+)-limonene & 40 & 42 & 42 & 43 & 45 & 44 & 43 & 45 & 45 & 45 & 46 & 47 & 50 & 50 & 50 & 52 \\
\hline & 2R, 5R-linalool oxide & 53 & 53 & 53 & 52 & 52 & 51 & 51 & 51 & 51 & 51 & 50 & 50 & 50 & 50 & 50 & 49 \\
\hline & S-(+)-linalool & 90 & 90 & 89 & 89 & 89 & 89 & 89 & 88 & 88 & 88 & 88 & 88 & 88 & 87 & 87 & 86 \\
\hline & R-(-)-carvone & 55 & 55 & 55 & 55 & 54 & 54 & 54 & 54 & 54 & 54 & 54 & 53 & 53 & 52 & 52 & 51 \\
\hline & S-(+)-carvone & 45 & 45 & 45 & 45 & 46 & 46 & 46 & 46 & 46 & 46 & 46 & 47 & 47 & 48 & 48 & 49 \\
\hline
\end{tabular}

${ }^{\text {a }}$ Storage conditions: UV (UV irradiation), $\mathrm{O}_{2}$ (oxygen exposure), $\mathrm{UV}-\mathrm{O}_{2}$ (UV irradiation-oxygen exposure); ${ }^{\mathrm{b}}$ control sample (con); ${ }^{\mathrm{c}}$ day (d). 
In conclusion, the enantiomer ratios of linalol, carvone, and linalool oxide were not significantly changed under different storage conditions, indicating that they had little effect on the flavor change of pepper oil. He et al. [12] found that the enantiomer of linalool in the hard tea beverage was more likely to be transformed at higher storage temperature $\left(45^{\circ} \mathrm{C}\right)$, while pepper oil was stored at $25^{\circ} \mathrm{C}$, which may be unfavorable to the transformation of linalol, carvone, and oxidized linalol enantiomers at this temperature [14]. Under $\mathrm{UV}-\mathrm{O}_{2}$, limonene was dominated by R-limonene in pepper oil from 20 days after storage, and the proportion of R-limonene gradually increased with the prolongation of storage time. Therefore, the transformation of limonene enantiomers played a certain role in the flavor change of pepper oil.

\subsection{Changes of Key Aroma Compounds under Different Storage Conditions}

It has been reported that many volatiles degrade and oxidize during extraction and storage. For example, monoterpenes in Yuzu (Citrus junos) steam-distilled oil can be converted to monoterpene alcohols and monoterpene oxides [15]. Rouseff et al. [16] found that light and oxygen were the main factors affecting the change of volatile components of citrus essential oils. Our previous study suggested that 1,8-cineole, (E)-2-heptenal, $\beta$-myrcene, $\beta$-ocimene, limonene, linalool, linalool oxide, and carvone were the key volatile flavor compounds in fried pepper oil [7]. On this basis, the effects of UV irradiation and oxygen exposure storage conditions on the changes of key aroma compounds during the storage period with storage time were investigated. The total contents of volatile compounds in pepper oil stored for 30 days under different storage conditions analyzed by SAFE-GC-MS were shown in Figure 1. The total content of volatile compounds in pepper oil decreased significantly after 30 days of storage, and the total amount under $\mathrm{UV}-\mathrm{O}_{2}$ storage conditions decreased the most, indicating that $\mathrm{UV}-\mathrm{O}_{2}$ storage conditions had the greatest impact on the volatile compounds of pepper oil.

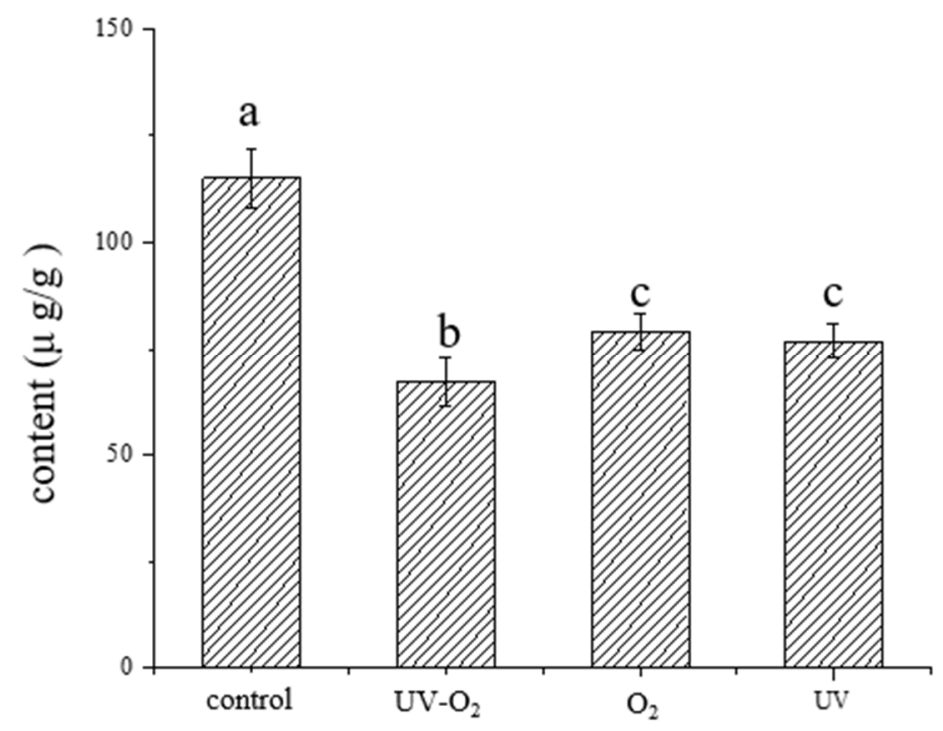

Figure 1. Total content of volatile compounds in fried pepper oil stored for 30 days under different storage conditions. Different letters are significantly different $(p<0.05)$. Tukey's post hoc test $(p<0.05)$ was performed to compare samples significantly different. Storage conditions: UV (UV irradiation), $\mathrm{O}_{2}$ (oxygen exposure), $\mathrm{UV}-\mathrm{O}_{2}$ (UV irradiation- oxygen exposure); control sample (con); day (d).

The variation of key aroma compounds in pepper oil with storage time under different storage conditions is shown in Figure 2. The contents of limonene, linalool, 1,8-cineole, $\beta$-myrcene, and $\beta$-ocimene showed a decreasing trend with storage time. Among them, the loss rate of limonene under $\mathrm{UV}-\mathrm{O}_{2}$ condition was the highest, followed by linalool under $\mathrm{UV}-\mathrm{O}_{2}$ storage condition (Figure 3 ), indicating that the combined action of $\mathrm{UV}$ and 
oxygen was more conducive to the degradation or oxidation of limonene and linalool, which were the main compounds that caused flavor attenuation of pepper oil during storage. Previous studies have shown that limonene was readily oxidized in the presence of oxygen. The oxidation of limonene initially leads to the formation of hydroperoxides [17] As with oxidized unsaturated fatty acids, limonene hydrogen peroxide could be further reacted to produce many products, including limonene oxide, carvone, permaryl acetate, and carvyl acetate [17]. Under acidic conditions, limonene can convert to $\alpha$-terpineol, which could impart a stale, musty, or piney odor to the product [18]. Limonene can also generate p-cymene through hydrogenation and double bond rearrangement reactions [19]. Baxter et al. [20] showed that linalool could be converted to $\alpha$-terpenol in a model solution containing aqueous citric acid solution under $24{ }^{\circ} \mathrm{C}$ within 20 days. $\beta$-Myrcene had the highest loss rate under $\mathrm{UV}-\mathrm{O}_{2}$ storage conditions, followed by oxygen exposure conditions, which indicated that the oxidation reaction was mainly occurred. Studies have shown that $\beta$-myrcene in Yuzu cold-pressed oil can be cyclized to produce $\gamma$-terpinene and terpinolene [19]. There was no significant difference in the loss rate of 1,8-cineole under different storage conditions. The loss rate of $\beta$-basilene increased rapidly under $\mathrm{UV}-\mathrm{O}_{2}$ conditions after 16 days of storage. In addition, compared with the aforementioned compounds, the contents of (E)-2-heptenal and linalool oxide showed an increasing trend with storage time. After 20 days of storage, the content of (E)-2-heptenal increased significantly, and the increase rate of (E)-2-heptenal was faster under $\mathrm{UV}-\mathrm{O}_{2}$ conditions, indicating that UV irradiation promoted the oxidation reaction of linoleic acid. Linalool oxide was the oxidation product of linalool. From 14 days of storage, the growth rate of its content increased significantly, and the effect of UV irradiation was more favorable to the oxidation of linalool. Under UV irradiation conditions, the content of carvone increased gradually during $0-12$ days of storage, then tended to balance, and showed an increasing trend under $\mathrm{UV}-\mathrm{O}_{2}$ and aerobic conditions. Therefore, the combined effect of $\mathrm{UV}$ and oxygen was the factor that caused flavor attenuation of pepper oil during storage. Sun et al. [9] compared the effects of sunlight, heat, and oxygen on the aroma degradation of grapefruit essential oil and found that the oily peculiar smell of grapefruit essential oil exposed to UV and oxygen conditions was stronger. This indicated that the combined action of UV radiation and oxygen also caused the aroma of grapefruit essential oil, which was consistent with the results that the combined effect of UV and oxygen was the key factor that caused flavor attenuation of pepper oil during storage.
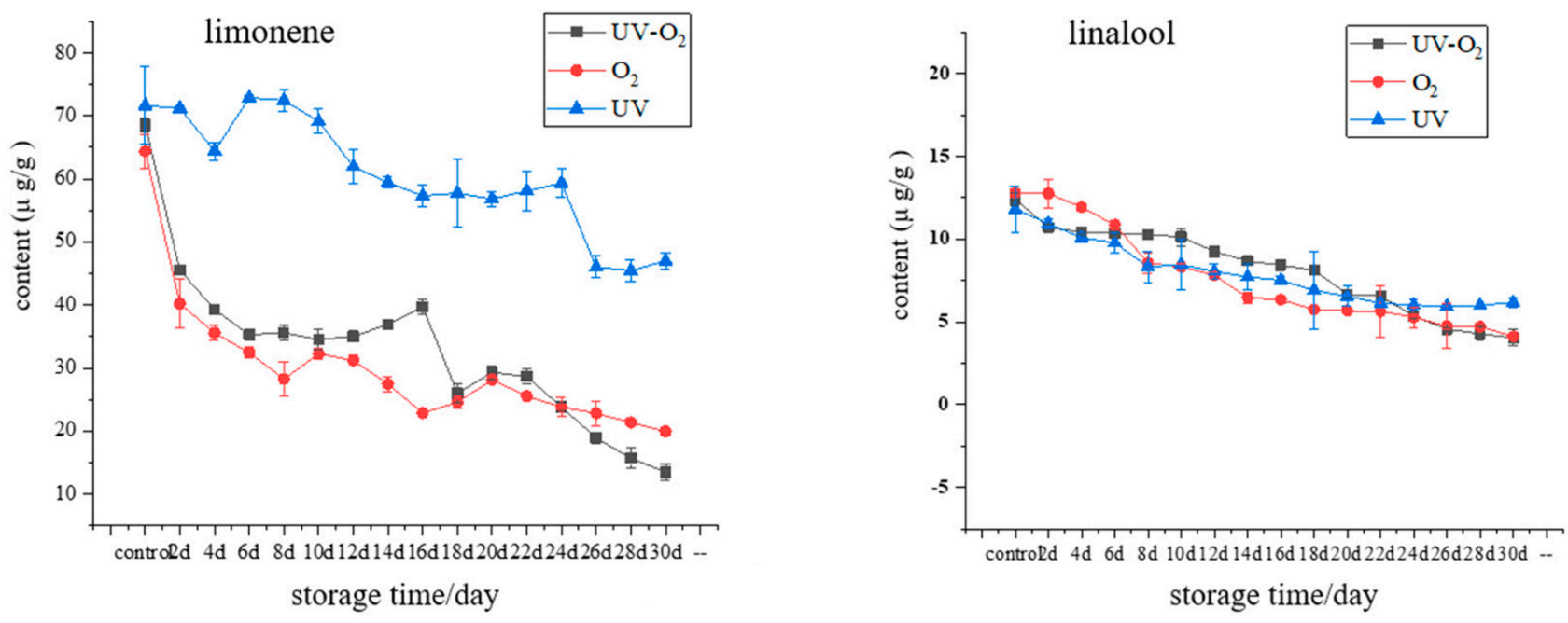

Figure 2. Cont. 

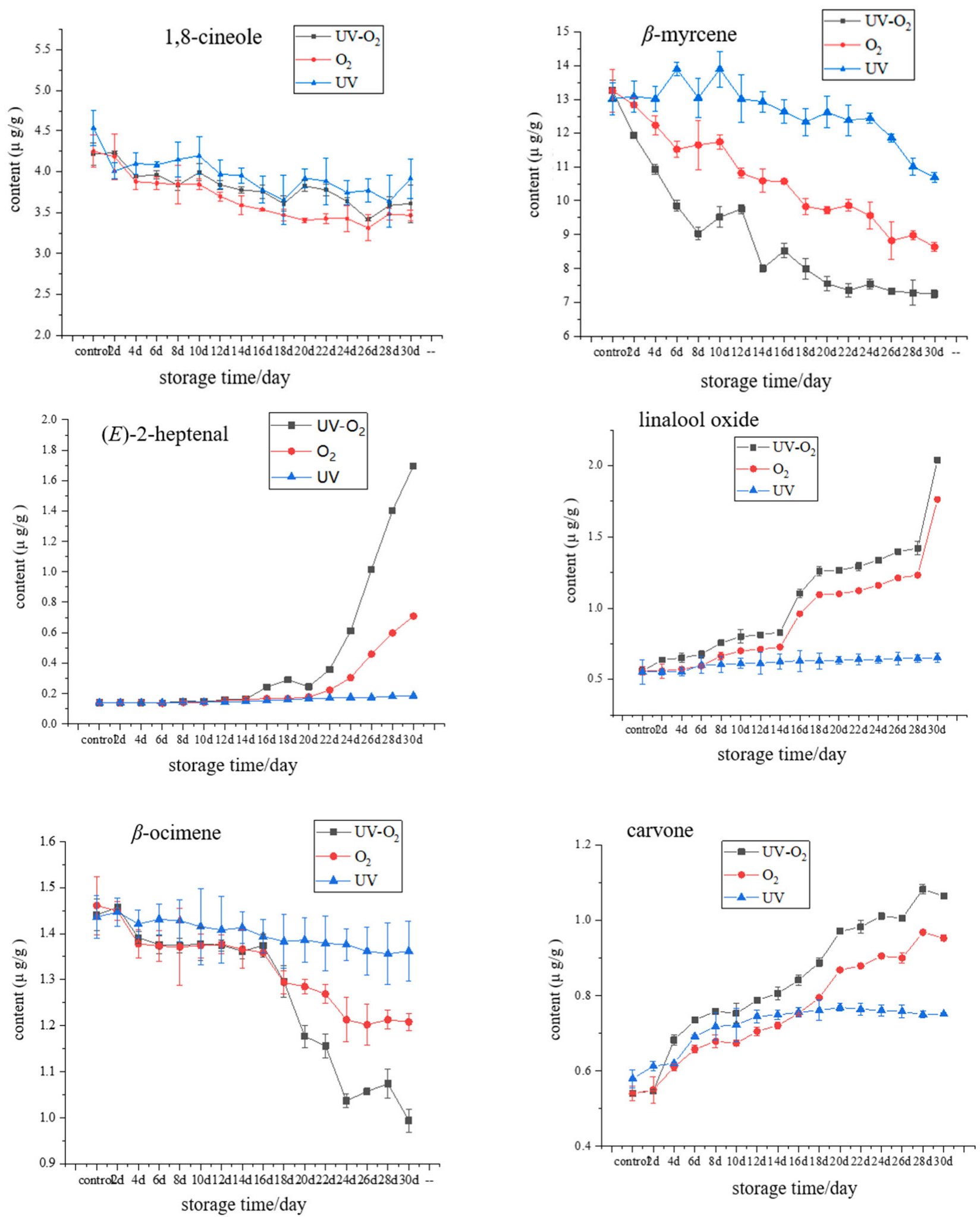

Figure 2. Variation of key aroma compounds in fried pepper oil under different storage conditions. 


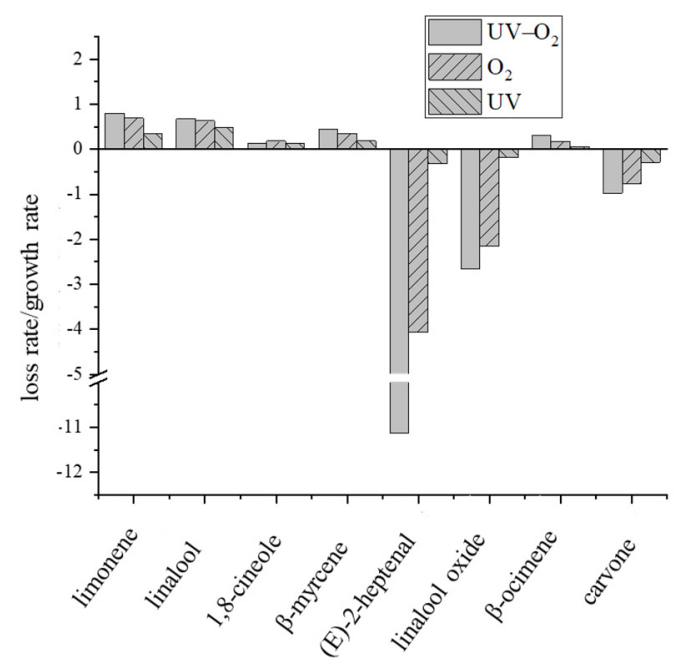

Figure 3. Loss rate/growth rate of key aroma compounds under different storage conditions. Storage conditions: UV (UV irradiation), $\mathrm{O}_{2}$ (oxygen exposure), $\mathrm{UV}-\mathrm{O}_{2}$ (UV irradiation-oxygen exposure); control sample (con); day (d).

\subsection{Investigation of the Volatile Changes under $\mathrm{UV}-\mathrm{O}_{2}$ Storage Condition}

To explore the more accurate changes of the volatile composition under $\mathrm{UV}-\mathrm{O}_{2}$ storage condition, the pepper oil samples were subjected to GC-MS analysis. A total of $52 \mathrm{com}$ pounds were detected in stored pepper oil (Table 3). Compared with the control pepper oil, the types of volatile compounds in the pepper oil stored for 30 days increased by 18, including alcohols, aldehydes, and ketones. Alcohols were derived primarily from the oxidation of aldehydes, such as hexanol, which was an oxidation product of hexanal. However, studies have shown that menthol can be converted from linalool. Linalool was first converted to citronellol by nucleophilic 1,3-transfer (allyl) in acid solution, and then citronellol was converted to menthol by cyclization [21]. Aldehydes and ketones were mainly derived from the oxidative degradation of fats, for example, as (E,E)-2,4-decadienal was the product of linoleic acid oxidation. 6-Methyl-5-heptene-2-ketone exhibited a rotted cabbage leaves odor and was produced in large quantities after 30 days of storage. It had been reported to be the main aromatic volatile in citrus fruits and exhibited remarkable changes in concentration after 25 days of irradiation [22]. In addition, (E)-limonene oxide, p-cymene, $\alpha$-terpineol, geranyl acetate, and (Z)-p-1,8-menadien-2-ol have increased significantly, which could be the oxidation or degradation products of limonene and linalool. Simon et al. [19] also found that limonene and $\beta$-myrcene had been significantly lost during storage at room temperature, whereas p-cymene and monoterpene alcohols increased during the same period. Therefore, the combined UV and oxygen exposure changed the volatile composition of fried pepper oil.

Table 3. Content of volatile compounds of newly prepared fried pepper oil (con) and fried pepper oil stored under $\mathrm{UV}-\mathrm{O}_{2}$ conditions for 30 days.

\begin{tabular}{|c|c|c|c|}
\hline \multirow{2}{*}{ Volatile } & \multicolumn{2}{|c|}{ Concentration $(\mu \mathrm{g} / \mathrm{g})$} & \multirow{2}{*}{ Identification $b$} \\
\hline & $\operatorname{con}^{a}$ & 30 Days & \\
\hline sabinene & $0.254 \pm 0.04^{a}$ & $0.245 \pm 0.05^{\mathrm{a}}$ & MS, RI, Std \\
\hline$\beta$-myrcene & $13.273 \pm 1.03^{a}$ & $7.259 \pm 0.23^{b}$ & MS, RI, Std \\
\hline limonene & $68.498 \pm 1.42^{\mathrm{a}}$ & $13.456 \pm 0.86^{b}$ & MS, RI, Std \\
\hline$\beta$-ocimene & $1.441 \pm 0.05^{\mathrm{a}}$ & $0.994 \pm 0.06^{b}$ & MS, RI, Std \\
\hline 1,8-cineole & $4.213 \pm 0.21^{\mathrm{a}}$ & $3.611 \pm 0.05^{b}$ & MS, RI, Std \\
\hline$\delta$-3-carene & $1.428 \pm 0.09^{\mathrm{a}}$ & $2.413 \pm 0.09^{b}$ & MS, RI, Std \\
\hline p-cymene & $0.294 \pm 0.02^{\mathrm{a}}$ & $1.901 \pm 0.1^{\mathrm{b}}$ & MS, RI, Std \\
\hline terpinolene & $0.102 \pm 0.01^{\mathrm{a}}$ & $0.196 \pm 0.06^{\mathrm{a}}$ & MS, RI, Std \\
\hline
\end{tabular}


Table 3. Cont.

\begin{tabular}{|c|c|c|c|}
\hline \multirow{2}{*}{ Volatile } & \multicolumn{2}{|c|}{ Concentration $(\mu \mathrm{g} / \mathrm{g})$} & \multirow{2}{*}{ Identification $^{b}$} \\
\hline & $\operatorname{con}^{a}$ & 30 Days & \\
\hline (E)-limonene oxide & $0.342 \pm 0.06^{\mathrm{a}}$ & $1.005 \pm 0.09^{b}$ & MS, RI, Std \\
\hline 1-octen-3-one & n.d. & $0.48 \pm 0.05$ & MS, RI, Std \\
\hline (E)-2-heptenal & $0.14 \pm 0.01^{\mathrm{a}}$ & $1.697 \pm 0.07^{b}$ & MS, RI, Std \\
\hline 6-methyl-5-hepten-2-one & n.d. & $1.452 \pm 0.04$ & MS, RI, Std \\
\hline cyclohexanone & n.d. & $0.04 \pm 0.006$ & MS, RI, Std \\
\hline 1-hexanol & n.d. & $0.552 \pm 0.07$ & MS, RI, Std \\
\hline (E,Z)-2,6-dimethyl-2,4,6-octatriene & $0.524 \pm 0.05^{\mathrm{a}}$ & $0.959 \pm 0.09^{b}$ & MS \\
\hline octanal & $0.23 \pm 0.02^{\mathrm{a}}$ & $0.574 \pm 0.04^{b}$ & MS, RI, Std \\
\hline (E,E)-2,4-hexadienal & n.d. & $0.486 \pm 0.03$ & MS, RI, Std \\
\hline perillen & $0.042 \pm 0.001$ & n.d. & MS, RI, Std \\
\hline$(\mathrm{E})$-2-octenal & n.d. & $2.916 \pm 0.12$ & MS, RI, Std \\
\hline 1-methyl-4-(1-methylethenyl)-benzene & $0.064 \pm 0.003^{\mathrm{a}}$ & $0.169 \pm 0.03^{b}$ & MS, RI, Std \\
\hline linalool oxide & $0.558 \pm 0.02^{\mathrm{a}}$ & $2.04 \pm 0.08^{\mathrm{b}}$ & MS, RI, Std \\
\hline 1-octen-3-ol & $0.028 \pm 0.003^{\mathrm{a}}$ & $1.219 \pm 0.14^{b}$ & MS, RI, Std \\
\hline 1-heptanol & n.d. & $1.19 \pm 0.11$ & MS, RI, Std \\
\hline acetic acid & $0.9 \pm 0.04^{\mathrm{a}}$ & $5.808 \pm 0.17^{b}$ & MS, RI, Std \\
\hline piperenone & $0.036 \pm 0.002^{\mathrm{a}}$ & $0.068 \pm 0.005^{\mathrm{a}}$ & MS, RI, Std \\
\hline (E,E)-2,4-heptadienal & $0.208 \pm 0.02^{\mathrm{a}}$ & $1.353 \pm 0.14^{b}$ & MS, RI, Std \\
\hline 4-ethylcyclohexanol & n.d. & $0.079 \pm 0.006$ & MS, RI, Std \\
\hline benzaldehyde & n.d. & $0.038 \pm 0.002$ & MS, RI, Std \\
\hline 4-methylcyclohex-3-en-1-one & n.d. & $0.245 \pm 0.01$ & MS \\
\hline menthol & n.d. & $0.109 \pm 0.007$ & MS, RI, Std \\
\hline p-ment-8-en-1-ol & $0.066 \pm 0.004^{\mathrm{a}}$ & $0.174 \pm 0.003^{b}$ & MS \\
\hline linalool & $12.414 \pm 0.32^{\mathrm{a}}$ & $4.049 \pm 0.25^{b}$ & MS, RI, Std \\
\hline linalyl acetate & $6.8 \pm 0.14^{\mathrm{a}}$ & $2.519 \pm 0.13^{b}$ & MS, RI, Std \\
\hline 1-octanol & n.d. & $0.39 \pm 0.09$ & MS, RI, Std \\
\hline 5-methyl furfural & $0.082 \pm 0.003$ & n.d. & MS, RI, Std \\
\hline caryophyllene & $0.048 \pm 0.004^{\mathrm{a}}$ & $0.036 \pm 0.004^{\mathrm{a}}$ & MS, RI, Std \\
\hline 6-methyl-3,5-heptadien-2-one & $0.03 \pm 0.001^{\mathrm{a}}$ & $0.06 \pm 0.006^{\mathrm{a}}$ & MS, RI, Std \\
\hline dihydrocarvone & n.d. & $0.479 \pm 0.001$ & MS \\
\hline terpinen-4-ol & $0.718 \pm 0.008$ & n.d. & MS, RI, Std \\
\hline 5-ethyl-2(5H)-furanone & n.d. & $2.122 \pm 0.07$ & MS \\
\hline (Z)-p-2,8-menadien-1-ol & $0.094 \pm 0.003^{\mathrm{a}}$ & $0.048 \pm 0.006^{\mathrm{b}}$ & MS \\
\hline (E)-2-decenal & n.d. & $0.574 \pm 0.007$ & MS, RI, Std \\
\hline$(2 \mathrm{E}, 4 \mathrm{E})-2,4$-decanedienal & n.d. & $0.086 \pm 0.002$ & MS, RI, Std \\
\hline 1-nonanol & n.d. & $0.185 \pm 0.003$ & MS, RI, Std \\
\hline (E,E)-2,4-dodecadienal & n.d. & $0.087 \pm 0.001$ & MS, RI, Std \\
\hline terpinyl acetate & $0.316 \pm 0.06^{\mathrm{a}}$ & $0.38 \pm 0.006^{\mathrm{a}}$ & MS, RI, Std \\
\hline$\alpha$-terpineol & $0.262 \pm 0.008^{a}$ & $0.352 \pm 0.007^{b}$ & MS, RI, Std \\
\hline piperitone & $0.052 \pm 0.002^{\mathrm{a}}$ & $0.055 \pm 0.002^{\mathrm{a}}$ & MS, RI, Std \\
\hline carvone & $0.54 \pm 0.007^{\mathrm{a}}$ & $1.06 \pm 0.049^{b}$ & MS, RI, Std \\
\hline neryl acetate & $0.078 \pm 0.001^{\mathrm{a}}$ & $0.15 \pm 0.003^{b}$ & MS, RI, Std \\
\hline $\begin{array}{l}\text { 6-ethenyltetrahydro-2,2,6-trimethyl-2H- } \\
\text { pyran-3-ol }\end{array}$ & $0.086 \pm 0.002^{\mathrm{a}}$ & $0.236 \pm 0.003^{b}$ & MS \\
\hline (Z)-p-1,8-menadien-2-ol & $0.082 \pm 0.007^{\mathrm{a}}$ & $0.264 \pm 0.006^{b}$ & MS \\
\hline (E)-carveol & $0.146 \pm 0.003^{\mathrm{a}}$ & $0.046 \pm 0.001^{b}$ & MS, RI, Std \\
\hline 2-(4-methylphenyl)propan-2-ol & $0.022 \pm 0.002$ & n.d. & MS \\
\hline$(\mathrm{Z})$-carveol & $0.082 \pm 0.001^{\mathrm{a}}$ & $0.041 \pm 0.001^{b}$ & MS, RI, Std \\
\hline 2-acetylpyrrole & $0.026 \pm 0.001^{\mathrm{a}}$ & $0.065 \pm 0.002^{b}$ & MS, RI, Std \\
\hline
\end{tabular}

a control sample (con). ${ }^{b}$ Identification based on Nist 14 mass spectral database (MS); published RIs; confirmed by authentic standards (Std). Means within different letters are significantly $(p<0.05)$ different for the same parameter. Tukey's post hoc test $(p<0.05)$ was performed to compare significantly different means and samples. 


\section{Conclusions}

In summary, the combined UV irradiation and oxygen exposure could cause remarkable aroma deterioration of pepper oil. Chiral compounds in the key aroma compounds of pepper oil include limonene, linalool, linalool oxide, and carvone. R-limonene dominated, and the main structure of other chiral enantiomers remained unchanged after 30 days of storage under $\mathrm{UV}-\mathrm{O}_{2}$ conditions. The transformation of limonene enantiomers played an important role in the flavor change of pepper oil. The loss or growth rate of key aroma compounds was the largest under $\mathrm{UV}-\mathrm{O}_{2}$ conditions, and the loss rate of limonene and linalool exhibited the highest under this condition. The aroma attenuation of pepper oil induced by combined UV and oxygen was confirmed to be caused by the degradation and transformation of limonene and linalool.

Author Contributions: Writing—original draft, J.S.; resources, N.Z., Y.Z. and H.Z.; writing—review and editing, B.S., F.R. and H.C.; funding acquisition, H.C. All authors have read and agreed to the published version of the manuscript.

Funding: This research was supported by the National Key R\&D Program of China (no. 2018YFD0400600).

Institutional Review Board Statement: Not applicable.

Informed Consent Statement: Informed consent was obtained from all subjects involved in the study.

Data Availability Statement: Not applicable.

Conflicts of Interest: The authors declare no conflict of interest.

\section{References}

1. Epifano, F.; Curini, M.; Carla Marcotullio, M.; Genovese, S. Searching for novel cancer chemopreventive plants and their products: The genus Zanthoxylum. Curr. Drug Targets 2011, 12, 1895-1902. [CrossRef] [PubMed]

2. Sakai, T.; Yoshihara, K.; Hirose, Y. Constituents of fruit oil from Japanese pepper. Bull. Chem. Soc. Jpn. 1968, 41, 1945-1950. [CrossRef] [PubMed]

3. Kusumoto, S.; Ohsuka, A.; Kotake, M.; Sakai, T. Constituents of leaf oil from Japanese pepper. Bull. Chem. Soc. Jpn. 1968, 41, 1950-1953. [CrossRef]

4. Jiang, L.; Kubota, K. Formation by mechanical stimulus of the flavor compounds in young leaves of Japanese pepper (Xanthoxylum piperitum dc.). J. Agric. Food Chem. 2001, 49, 1353-1357. [CrossRef]

5. Jiang, L.; Kubota, K. Differences in the volatile components and their odor characteristics of green and ripe fruits and dried pericarp of Japanese pepper (Xanthoxylum piperitum, DC.). J. Agric. Food Chem. 2004, 52, 4197-4203. [CrossRef] [PubMed]

6. Yang, X. Aroma constituents and alkylamides of red and green Huajiao (Zanthoxylum bungeanum and Zanthoxylum schinifolium). J. Agric. Food Chem. 2008, 56, 1689-1696. [CrossRef]

7. Sun, J.; Sun, B.G.; Ren, F.Z.; Chen, H.T.; Zhang, N.; Zhang, Y.Y. Characterization of key odorants in Hanyuan and Hancheng fried pepper (Zanthoxylum bungeanum) oil. J. Agric. Food Chem. 2020, 68, 6403-6411. [CrossRef] [PubMed]

8. Wibowo, S.; Grauwet, T.; Kebede, B.T.; Hendrickx, M. Study of chemical changes in pasteurised orange juice during shelf-life: A fingerprinting-kinetics evaluation of the volatile fraction. Food Res. Int. 2015, 75, 295-304. [CrossRef]

9. Sun, H.; Ni, H.; Yang, Y.Y.; Wu, L.; Cai, H.N.; Xiao, A.F.; Chen, F. Investigation of sunlight-induced deterioration of aroma of Pummelo (Citrus maxima) essential oil. J. Agric. Food Chem. 2014, 62, 11818-11830. [CrossRef]

10. Cheng, H.X.; Yuan, Y.L.; Hu, L.L.; Qiu, P.; Chen, H.F.; Dou, J.W.; Dong, S.Y. Effect of storage conditions on limonene and linalool of Zanthoxylum bungeanum seed oil. Food Sci. 2014, 35, 258-261.

11. Yuan, F.; He, F.; Qian, Y.L.; Zheng, J.; Qian, M.C. Aroma stability of lemon-flavored hard iced tea assessed by chirality and aroma extract dilution analysis. J. Agric. Food Chem. 2016, 64, 5717-5723. [CrossRef]

12. He, F.; Qian, Y.P.L.; Qian, M.C. Flavour and chiral stability of lemon-flavored hard tea during storage. Food Chem. 2017, 239, 622-630. [CrossRef]

13. Ruiz del Castillo, M.L.; Caja, M.M.; Herraiz, M. Use of the enantiomeric composition for the assessment of the authenticity of fruit beverages. J. Agric. Food Chem. 2003, 51, 1284-1288. [CrossRef] [PubMed]

14. Bonnländer, B.; Cappuccio, R.; Liverani, F.S.; Winterhalter, P. Analysis of enantiomeric linalool ratio in green and roasted coffee. Flavor Frag. J. 2006, 21, 637-641. [CrossRef]

15. Kashiwagi, T.; Lan Phi, N.T.; Sawamura, M. Compositional changes in Yuzu (Citrus junos) steam-distilled oil and effects of antioxidants on oil quality during storage. Food Sci. Technol. Res. 2010, 16, 51-58. [CrossRef]

16. Rouseff, R.L.; Ruiz Perez-Cacho, P.; Jabalpurwala, F. Historical review of citrus flavor research during the past 100 years. J. Agric. Food Chem. 2009, 57, 8115-8124. [CrossRef] [PubMed] 
17. Pérez-López, A.J.; Saura, D.; Lorente, J.; Carbonell-Barrachina, Á.A. Limonene, linalool, a-terpineol, and terpinen-4-ol as quality control parameters in mandarin juice processing. Eur. Food Res. Technol. 2006, 222, 281-285. [CrossRef]

18. Haleva-Toledo, E.; Naim, M.; Zehavi, U.; Rouseff, R.L. Formation of $\alpha$-terpineol in citrus Juices, model and buffer solutions. J. Food Sci. 1999, 64, 838-841. [CrossRef]

19. Njoroge, S.M.; Ukeda, H.; Sawamura, M. Changes in the volatile composition of Yuzu (Citrus junos Tanaka) cold-pressed oil during storage. J. Agric. Food Chem. 1996, 44, 550-556. [CrossRef]

20. Ohta, H.; Tonohara, K.; Watanabe, A.; Iino, K.; Kimura, S. Flavor specificities of Satsuma mandarin juice extracted by a new-type screw press extraction system. Agric. Biol. Chem. 1982, 46, 1385-1386.

21. Yang, Y.; Jin, G.J.; Wang, X.J.; Kong, C.L.; Liu, J.B.; Tao, Y.S. Chemical profiles and aroma contribution of terpene compounds in Meili (Vitis vinifera L.) grape and wine. Food Chem. 2019, 284, 155-161. [CrossRef] [PubMed]

22. Qiao, Y.; Xie, B.J.; Zhang, Y.; Zhang, Y.; Fan, G.; Yao, X.L.; Pan, S.Y. Characterization of aroma active compounds in fruit juice and peel oil of jin chen sweet orange fruit (Citrus sinensis (L.) osbeck) by GC-MS and GC-O. Molecules 2008, 13, 1333-1344. [CrossRef] [PubMed] 